Rev. Latinoam. Psicopat. Fund., São Paulo, v. 14, n. 3, p. 452-471, setembro 2011

\title{
Oliver Sacks e a "neurofenomenologia do self"
}

Sergio Gomes da Silva

A neurologia é um ramo da medicina que busca estudar uma diversidade de distúrbios neurológicos tais como perda da fala, da linguagem, da memória, da visão, da percepção dos sentidos e da identidade, entre outros distúrbios, e construiu um conjunto de conhecimentos específicos, sobretudo a partir do desenvolvimento da tecnologia médica através de modernos aparelhos de imagem cerebral. Este trabalho objetiva analisar as contribuições do neurologista Oliver Sacks a partir daquilo que ele definiu como uma "neurofenomenologia do self", da subjetividade, da identidade e da imagem corporal. Evidencia-se a abordagem fenomenológica em conjunto com as contribuições da neurologia e ressalta-se o papel da subjetividade buscando novas narrativas da mente.

Palavras-chave: Neurofenomenologia, self, subjetividade, identidade, imagem-corporal 
O corpo é o veículo do ser no mundo, e ter um corpo é, para um ser vivo, juntar-se a um meio definido, confundir-se com certos projetos e empenhar-se continuamente neles.

Merleau-Ponty, Fenomenologia da percepção

\section{Introdução}

A neurologia foi uma das ciências que mais se desenvolveu nos últimos tempos, sobretudo após os avanços das tecnologias de imagem cerebral. Os diversos distúrbios neurológicos tais como perda da fala, da linguagem, da memória, da visão, da percepção dos sentidos e da identidade, foram estudados largamente e construído um conjunto de conhecimentos específicos para cada um deles, e muito do que se pensava sobre as causas fisiológicas ou psíquicas desses danos, caiu por terra com o avanço da tecnologia médica.

Desde o final do século XIX, a pesquisa científica de inúmeros neurologistas sobre o cérebro humano foi a responsável por estabelecer definitivamente uma relação entre cérebro e mente, cérebro e corpo e, finalmente, corpo e mente.

Rev. Latinoam. Psicopat. Fund., São Paulo, v. 14, n. 3, p. 452-471, setembro 2011 
Paul Broca foi um deles. Ao descobrir uma área específica do hemisfério esquerdo do cérebro como a responsável pelos distúrbios da fala, em 1861, ele abriu caminho para que outro neurologista famoso, Freud, atribuísse uma base fisiológica aos problemas da fala (Freud, 1891a). Desde então, as pesquisas e o mapeamento do cérebro humano não pararam mais.

A neurologia tornou-se, portanto, uma "ciência personalista" ao comprovar que os acidentes vasculares cerebrais ou demais danos ao cérebro, tal como foi vítima Phineas Gage, também afetavam a personalidade e a identidade do sujeito, sua "persona", sua subjetividade, seu próprio "eu".

Numerosos casos clínicos comprovaram essa sentença, tais como aqueles analisados por Oliver Sacks em muitos de seus livros (Sacks, 1995; 1997; 2003). Seus pacientes, transformados em personagens em uma vasta produção literária, trouxeram à tona uma gama de distúrbios do comportamento com origens eminentemente causadas por danos ao cérebro: um pintor que passou a enxergar tudo em preto e branco; uma mulher que perdeu a sensação da propriocepção; o homem que passou a perceber membros fantasmas no seu corpo; um jovem que perde a noção do tempo tendo sua memória restrita à década de 1960, quando ocorreu seu acidente; um deficiente visual que volta a enxergar após uma cirurgia e tenta se adaptar ao mundo que nunca viu; o cirurgião que passa a ter tiques nervosos ou ainda um neurologista famoso que perde a sensação e percepção da própria perna, entre outros, são todos personagens do fantástico universo de Oliver Sacks. Muitos dos seus personagens tiveram suas histórias publicadas em revistas tais como The New Yorker e The New York Times, mais tarde em livros e posteriormente em filmes e peças de teatro. ${ }^{1}$

Em todos os casos, verificamos vividamente o esforço do neurologista em não deixar de lado as ferramentas que a ciência médica dispõe. Mas o que transforma Sacks em um neurologista diferente da maioria, é que ele apontou para algo que ainda não havia sido feito: ele passou a deixar seus pacientes falarem sobre si mesmos e sobre seus distúrbios, tais como psicólogos e psicanalistas têm feito há décadas, dando passagem para a subjetividade de seus pacientes.

Sacks se tornou um proeminente intérprete das desordens neurológicas na cultura anglo-americana, tornando-se uma celebridade no mundo acadêmico. No início de sua carreira, ele inspirou a prática daquilo que chamou de "neurologia

1. Os filmes são: At First Sight (À primeira vista) - Direção de Irwin Winkler - MGM/United Artists, 1999; Awakening (Tempo de despertar) - Direção de Penny Marshall - Columbia/ Tristar Pictures, 1990. A peça de teatro chama-se The Man Who Mistook his Wife for a Hat (O homem que confundiu sua mulher com um chapéu) - Direção de Peter Brooks, Royal National Theatre, junho de 1994.

Rev. Latinoam. Psicopat. Fund., São Paulo, v. 14, n. 3, p. 452-471, setembro 2011 
romântica", ou seja, uma neurologia que recobre a subjetividade de seus pacientes em vez de unicamente as condições fisiológicas engendradas pela neurologia tradicional.

Com isso, o neurologista Sacks praticamente "atualiza" o neurologista Freud naquilo em que ele fez de mais singular e específico - a cura pela palavra. Sacks não desperdiça os laudos médicos de exames neurológicos complexos, mas deixa a palavra e as descrições narrativas e subjetivas de seus pacientes tomarem forma.

Munido de seus conhecimentos como neurologista e somado a uma leitura particular da filosofia, da psicologia e, sobretudo, da psicanálise, Sacks busca as raízes da subjetividade humana por meio de uma atenta observação do comportamento de seus pacientes e de uma escuta clínica sobre o que eles têm a dizer antes e depois de lesões cerebrais, muitas vezes graves, sobre sua história de vida, sobre o que eles foram, sobre o que eles se tornaram e sobre o que eles pensam como serão daí para frente. Sacks não se reduz a uma descrição biológica nem fisicalista nem mentalista da vida subjetiva, mas se utiliza da mesma técnica que fez a psicanálise ser conhecida como uma talking cure.

A consequência disso é que Sacks, apesar de não construir uma teoria inovadora acerca da construção da imagem do corpo, da subjetividade e da identidade pessoal, passa a fazer uso das teorias disponíveis no campo fenomenológico para auxiliá-lo nas descrições subjetivas de diversos distúrbios neurológicos de seus pacientes sem, no entanto, desprezar as descrições dos mesmos distúrbios pelas mais modernas técnicas médicas para análise e tratamento.

Assim sendo, ele não restringe ao seu arsenal de conhecimentos médicos e científicos, nem faz da cadeia de redes neuronais predicativa de nossas subjetividades. Ele não as nega, mas não se restringe a elas como veremos a seguir.

\section{A "neurologia da identidade"}

Logo no início do livro $O$ homem que confundiu sua mulher com um chapéu, Oliver Sacks (1997) afirma: "Para devolver o sujeito humano ao centro - o ser humano sofredor, torturado, em luta - devemos aprofundar um relato de caso transformando-o em uma narrativa ou história; só então teremos um 'quem' além de um 'o que', uma pessoa real, um paciente, em relação à doença - em relação ao físico" (p. 10).

Sacks afirma que a gama de distúrbios neurológicos com os quais se deparou ao longo de sua vida enquanto médico, o fez cada vez mais necessitar de um aporte maior do que aquele dado pelos instrumentos de que dispunha pela

Rev. Latinoam. Psicopat. Fund., São Paulo, v. 14, n. 3, p. 452-471, setembro 2011 
medicina tradicional ou pela tecnologia médica, um estudo aprofundado sobre cada um dos distúrbios de seus pacientes, somado a uma descrição da doença e da vida pessoal destes, o que exigiu a concepção de uma nova disciplina: a "neurologia da identidade".

A neurologia da identidade, de acordo com o autor, é aquela que lida diretamente com as bases neurais do "eu" e com o problema "mente e cérebro". Para tanto, a descrição da vida subjetiva tornou-se necessária para compreensão dos danos cerebrais. Unir psíquico e físico, só seria possível pela via narrativa de si. Ora, mas não foi exatamente essa a proposição de Freud quando "inventou a psicanálise"?

Lúria (1981) em Fundamentos da neuropsicologia foi um dos neurologistas que mais estudou as consequências de lesões cerebrais das mais diversas formas e a capacidade do cérebro de se adaptar a uma nova realidade. De acordo com Sacks, a ocorrência dessas adaptações exigia uma nova visão do cérebro não mais como programado e estático, mas um cérebro dinâmico e ativo, ou seja, um complexo sistema capaz de se adaptar às mudanças e necessidades do organismo. Essas mudanças fizeram com que o organismo tivesse necessidade de criar um novo centro identitário, um novo "eu" em um mundo coerente com sua nova realidade.

Vários neurologistas contemporâneos a Freud já haviam avançado nos estudos sobre a correspondência entre danos cerebrais e as perturbações da alma. Entre eles, Babinski e o próprio Freud, sob a batuta de Charcot, buscaram diferenciar a paralisia orgânica, portanto, neurológica, das paralisias histéricas (Freud, 1886; 1888b). De acordo com Ehrenberg (2004), a histeria foi a patologia que permitiu construir a ideia de psiquismo na época de Freud e lhe deu um conteúdo diferenciado da ideia de lesão cerebral, visto que, para falar de doença, era necessário que houvesse uma lesão para explicá-la. Não obstante, foi Charcot quem rompeu com essa ideia ao empregar o termo "lesão funcional" ou "dinâmica", considerando a histeria como uma patologia autêntica do campo da neurologia. A prova disso era a possibilidade de hipnotizar as histéricas produzindo uma reação fisiológica, e não psicológica.

Freud havia constatado três padrões neuroanatômicos para as paralisias orgânicas, além de traumas e sistemas psíquicos reprimidos para as paralisias histéricas. A primeira tem uma base anatômica, enquanto a segunda tem uma base psíquica ou psicodinâmica. Para Freud, as paralisias orgânicas eram físicas enquanto as paralisias histéricas eram mentais (Sacks, 2003).

Babinski, por sua vez, escrevera os relatos dos seus estudos sobre paralisias, alienações, lesões periféricas, entre outras, em uma época anterior aos escritos de Head e Sherrington, sobre imagem e esquema corporal, antevendo que esses distúrbios teriam uma raiz em determinadas áreas localizadas no cérebro

Rev. Latinoam. Psicopat. Fund., São Paulo, v. 14, n. 3, p. 452-471, setembro 2011 
(Sacks, 2003). Babinski, portanto, pautava seus estudos em um aporte biológico e fisiológico dos distúrbios neuronais. Sua contribuição nesse campo foi ter estabelecido uma nítida fronteira entre o psicológico e o neurológico, possibilitando a compreensão de estados mentais em estados cerebrais, situando-se frontalmente em oposição a Freud (Ehrenberg, 2004).

Sigmund Freud, ao contrário, instituiu uma nova ciência da mente e do cérebro com a psicanálise. Ele forneceu um conteúdo particular à noção de psíquico que emergia à sua época, qual seja, a ideia de subjetividade pela abertura dos portões do inconsciente através da palavra, demonstrando que algo mais se passava no corpo das histéricas.

Lúria (1981), por sua vez, e com os eventos que se seguiram à Segunda Guerra Mundial, instituiu aquilo que viria a ser conhecida como "neuropsicologia", na qual buscava as raízes de doenças como resultante de danos causados ao hemisfério esquerdo do cérebro, transformando a neurologia naquilo que Sacks descreve como sendo uma "ciência da personalidade" ou "ciência personalista". A neurologia clássica, diz Sacks, consolidou-se na década de 1920. A neuropsicologia, por outro lado, consolidou-se na década de 1950. O que precisamos agora, diz o autor, é uma neurologia do "eu", do self, da identidade (Sacks, 2003).

A correlação entre danos cerebrais e a construção da imagem do corpo foi o mote necessário para que pesquisadores, neurologistas e neurocientistas atentassem para o fato e ressaltassem a importância de buscar na "carne do cérebro" o referente último da imagem corporal.

Portanto, para Sacks, toda doença neurológica é, na verdade, uma luta para preservar a identidade do sujeito como ela foi constituída.

Percebi claramente que tais experiências tinham origem fisiológica, mas também que não podiam ser enquadradas no modelo clássico. Ficou claro para mim que precisávamos de uma "neurologia da identidade", uma neurologia que pudesse explicar como diferentes partes do corpo (e seu espaço) podiam ser "possuídas" (ou "perdidas"), uma base neurológica para a coerência e unificação da percepção (especialmente depois de uma perturbação da percepção por lesão ou doença). Precisávamos de uma neurologia que pudesse escapar do rígido dualismo mente/corpo, das rígidas noções fisicistas de algoritmo e gabarito, uma neurologia capaz de fazer jus à riqueza e densidade da experiência, seu senso de cena e música, sua pessoalidade, seu fluxo sempre mutável de experiência, de história, de tornar-se. (Sacks, 2003, p. 195)

Sacks rompe com o domínio fisicalista das bases neurais do "eu", que via no cérebro unicamente o "ponto de mutação" da identidade e da subjetividade, apesar de fazer uso do mesmo vocabulário técnico da disciplina que faz parte.

Rev. Latinoam. Psicopat. Fund., São Paulo, v. 14, n. 3, p. 452-471, setembro 2011 


\section{Vinhetas clínicas}

Entre inúmeros casos analisados pelo neurologista Oliver Sacks, gostaríamos de trazer para discussão dois casos para ilustrar suas teses acerca da construção da imagem do corpo, ressaltando aquilo que descrevemos como sendo uma "neurofenomenologia do self" em sua prática clínica.

A neurofenomenologia foi um termo introduzido por Francisco Varela no início da década de 1990 e combina os aportes teóricos da neurociência com os da fenomenologia no estudo da consciência. Segundo o autor, a neurofenomenologia sugere que invariantes padrões e estruturas da "consciência da primeira pessoa" podem encontrar explicações na fisiologia e no funcionamento do cérebro. Teoricamente, a neurofenomenologia busca encontrar as raízes da "corporificação" (embodiment) na neurofisiologia da consciência e na experiência subjetiva no atributo da primeira pessoa. Sacks não discute a construção de um centro identitário tal qual um "eu" holístico a partir da neurofenomenologia na forma conferida por Varela (1996) e Varela \& Shear (1999), porém, assim como ele não despreza o cérebro e suas conexões na construção de uma imagem do "eu", do corpo, da identidade e da subjetividade, ele também faz uso dos aportes teóricos da fenomenologia, conforme veremos.

\section{A mulher "desencarnada"}

Christina tem 27 anos e é programadora de computador. Casada, mãe de dois filhos, é descrita como tendo uma mente e um corpo fortes. Inteligente e culta, é apreciadora de balé e de poesia. Teve poucos episódios de doença e nunca se lembrou de ter ficado acamada durante muitos dias. Após sofrer fortes dores abdominais, verificou-se que tinha cálculos biliares ficando internada para remoção da vesícula. No dia anterior à cirurgia, teve um sonho onde não conseguia sentir nem suas mãos, nem suas pernas, deixando cair tudo que lhe fosse solicitado segurar ou sendo incapaz de dar um passo. Foi atendida por um psiquiatra que diagnosticou "ansiedade pré-operatória".

No mesmo dia, o sonho tornara-se realidade e Christina não mais passou a sentir as pernas nem as mãos por completo. Não conseguia andar nem segurar nada com as mãos ao menos se olhasse para eles. Perdera a sensação do seu próprio corpo. Não conseguia mais se sentar, pois seu corpo cedia. Desenvolveu em pouquíssimo tempo uma estranha expressão facial, com mandíbula caída e sem postura vocal. Algo terrível havia acontecido àquela mulher: "Não consigo sentir meu corpo. Eu me sinto esquisita - desencarnada". 
Se para a psicanálise, Christina poderia ser "diagnosticada" através do modelo clássico de histeria de conversão (tal como era corrente no final do século XIX e de acordo com as proposições de Charcot, Freud e Breuer à época), para Sacks (1997), Christina apenas perdera completamente toda a noção de propriocepção do seu próprio corpo (p. 61).

\section{O neurologista com uma perna só}

O neurologista Oliver Sacks, de férias, resolve esquiar nas montanhas. Subestimando os avisos de que haveria uma tempestade se aproximando e de animais bravos no lugar onde escolhera para esquiar, resolve ir assim mesmo pegar uma trilha e satisfazer seu objetivo. Apesar da inclinação do terreno, o neurologista possuía pernas fortes adquiridas através de anos de exercícios árduos em academia de musculação. Mas ao tentar fugir de um animal que aparecera à sua frente, escorrega e quebra a perna esquerda.

Resgatado, vai para um hospital, tem a perna engessada e fica internado até descobrir que perdera toda a sensação do referido membro. De eminente e respeitado profissional da área médica, o Sacks neurologista torna-se o Sacks paciente e, para seu horror e constatação, descobre que tem um "objeto estranho" agarrado ao seu próprio corpo: sua perna esquerda.

"Quando não era uniforme, a perna tendia a ficar presa em todo tipo de irregularidade - parecia curiosamente inepta para evitá-la -, e eu a xinguei várias vezes de 'estúpida' ou 'insensível'” (Sacks, 2003, p. 24). Diagnóstico de Sacks: perda da representação da imagem da perna ou, dito de outro modo, perda da propriocepção da perna, diferentemente do diagnóstico de histeria clássica.

Ainda há de se pontuar dois outros casos descritos por Sacks com perda da propriocepção e da imagem corporal. O primeiro é o caso de Madeleine, sessenta anos, internada em um hospital em 1980 com cegueira congênita e paralisia cerebral. Apresentava ainda hipertonia e atetose, ou seja, movimentos involuntários das mãos, aos quais, segundo Sacks, não se acrescentavam o não desenvolvimento dos olhos. Poderia se esperar uma pessoa com retardo mental, mas Madeleine era extremamente culta. Sacks deduz que ela teria facilidade de ler em braile, mas afirma que todo o seu conhecimento se deu por meio de leituras próprias feitas com ajuda de pessoas ou gravações em fitas.Não podia ler em braile, pois, segundo ela, não podia fazer nada com as mãos. "Elas são completamente inúteis. Monte de massa imprestáveis e esquecidos - elas nem parecem fazer parte de mim", diz a combalida senhora. As capacidades sensoriais das mãos de Madeleine, ao contrário, estavam intactas, porém, sua propriedade proprioceptiva estava completamente prejudicada devido à paralisia cerebral. $\mathrm{O}$ 
outro caso trata-se do senhor MacGregor, um homem cuja percepção proprioceptiva de seu corpo estava danificada: ele andava inclinado tal qual a Torre de Pisa e era totalmente alheio a esse fato. Mais do que uma referência aos órgãos do equilíbrio, o senhor MacGregor não conseguia integrar os três sentidos necessários ao seu equilíbrio corporal: o sistema labiríntico, o proprioceptivo e o campo visual (Sacks, 1997).

Em todos estes casos, Sacks não abandona uma possibilidade de que tenha havido em algum momento, um distúrbio neurológico para as síndromes descritas, talvez um pequeno derrame ou isquemia cerebral. Não obstante, não fica reduzido a esta conformidade. Para ele, muito mais do que um dano no córtex cerebral é preciso que se entenda que a imagem do corpo, tal como entendido pela fenomenologia da percepção, é uma construção dada pelos sentidos do próprio corpo, mas não apenas aqueles que conhecemos referentes aos órgãos dos sentidos.

\section{O sentido do corpo}

De modo geral, aprendemos que o corpo humano possui cinco sentidos: tato, visão, audição, paladar e olfato. É por meio desses cinco sentidos que apreendemos, percebemos e nos relacionamos com o mundo a nossa volta. Mas isto não é verdade. Possuímos um sentido a mais: a propriocepção.

A propriocepção, segundo Sacks, pode ser compreendida como sendo um "sexto sentido", ou seja, um sentido inconsciente ou não de que nos movemos no espaço. A propriocepção é inerente às partes móveis do nosso corpo (músculos, ossos, tendões, articulações, pele etc.), por meio da qual tomamos conhecimento do nosso corpo no mundo e é indispensável para o senso de "nós mesmos". Ela foi descrita pela primeira vez na década de 1890 por Sherrington, que a diferenciou da "exterocepção". Graças à propriocepção, sentimos que temos um corpo, que ele é uma propriedade, nossa propriedade, assim como percebemos que temos um "eu" (Sacks, 1997).

O sentido do corpo, para Sacks, é dado por três dispositivos que se interpenetram: a visão, os órgãos do equilíbrio (sistema vestibular) e a propriocepção, todos trabalhando juntos. Quando um desses dispositivos falha, os outros tendem a compensá-lo.

Não obstante, a propriocepção, a exterocepção e a interocepção são processos na autopercepção do próprio corpo, e necessários para se diferenciar imagem e esquema corporal.

A exterocepção e a interocepção orientam nosso movimento no eixo gravitacional e organizam a experiência da totalidade corporal a partir da

Rev. Latinoam. Psicopat. Fund., São Paulo, v. 14, n. 3, p. 452-471, setembro 2011 
experiência de partes localizadas no próprio corpo. A interocepção, assim, é toda a percepção da interioridade do corpo, aí incluídos os movimentos das vísceras, enquanto a exterocepção está voltada para a percepção a tudo o que é exterior ao corpo, ou seja, os objetos externos e os eventos do ambiente, proporcionados pelos órgãos dos sentidos. A primeira estrutura a experiência do próprio corpo enquanto a segunda organiza os fenômenos extracorporais (Costa, 2004).

A propriocepção, como também define Butterworth (1998), é uma copercepção do "eu" (self) e do ambiente que o cerca, é um mecanismo de autossensibilidade comum a todo o sistema perceptivo, cuja consciência dos movimentos pode ser obtida através tanto da visão quanto da audição, tanto dos músculos quanto das articulações.

De acordo com essa perspectiva, há uma simultaneidade perceptiva entre o "eu" e o mundo, necessária para a autopercepção de si. Assim, tanto a interocepção quanto a propriocepção são formas diversas do corpo se autoperceber em sua relação direta com os objetos que o cercam e os eventos do mundo.

Como diz Sacks, os sentidos da propriocepção são "os olhos do corpo" ou o modo como o corpo se vê. Quando ela desaparece, é como se o corpo estivesse cego. "Meu corpo não consegue 'enxergar' a si mesmo se perdeu seus olhos, certo? Por isso, preciso olhar para ele - ser os olhos de meu corpo", diz Christina, paciente de Sacks. Durante seu tratamento e recuperação da mobilidade de seu corpo, ela foi pouco a pouco substituindo o feedback normal e inconsciente da propriocepção pelo feedback inconsciente da visão. Sua imagem corporal perdida foi sendo reintegrada à medida que seu sistema perceptivo da visão passou a agir como o centro motor do seu corpo.

Mas à medida que o tempo passa, ela ainda sentia com persistência a perda da propriocepção do seu corpo, como se ele estivesse morto, irreal, como se não fosse o corpo dela, nem que ela pudesse se apropriar dele. Como tal sensação nunca fizera parte de sua experiência subjetiva, Christina não encontra palavras nem analogias diretas para descrever a escuridão, o silêncio e a mudez do seu próprio corpo: "Sinto que meu corpo está cego e surdo para si mesmo... ele não tem o senso de si mesmo" (Sacks, 1997).

De modo análogo é o modo como Madeleine, a mulher que perdera a propriocepção de seus membros se expressa, ao afirmar que suas mãos nada mais são do que um monte de massa imprestável ou como a falta de percepção corporal do senhor MacGregor, um homem que tem seu corpo inclinado ao caminhar.

É nesse mesmo sentido que "Sacks paciente" se expressa: "Eu não conheci minha perna. Ela me era totalmente estranha, desconhecida, não era minha. Fitei-a absolutamente sem reconhecimento. (...) Era absolutamente não-eu" (Sacks, 2003, p. 62).

Rev. Latinoam. Psicopat. Fund., São Paulo, v. 14, n. 3, p. 452-471, setembro 2011 
Christina era uma mulher sem corpo, MacGregor não tinha consciência do seu corpo, Madeleine era uma mulher sem mãos e Sacks, por conseguinte, era um homem sem a perna esquerda. Tanto na esfera neurológica como na esfera neuropsicológica ou neurofenomenológica, o que ocorrera com esses pacientes era a perda da imagem corporal. De Christina e MacGregor, de todo o envelope corpóreo; de Sacks e Madeleine, da imagem interna ou representação da própria perna ou mãos. De acordo com o neurologista, havia nesses casos uma obliteração da representação da imagem do corpo no cérebro.

Christina era, em certo sentido, uma mulher "desmedulada", "desencarnada", uma alma penada, ela "possuía um corpo sem dono", não havia nenhuma propriedade que lhe desse qualquer autonomia do seu próprio corpo, tal como descreve Sacks (1997):

Ela perdera junto com o senso de propriocepção, o ancoradouro orgânico fundamental da identidade - pelo menos da identidade corporal, ou "ego corporal" que Freud considerava a base do eu. (...) Deve ocorrer alguma despersonalização ou "desrealização" semelhante na presença de graves distúrbios da percepção ou imagem corporal. (p. 68)

De modo análogo, assim Oliver Sacks (2003) descreve seu distúrbio:

Eu era um amputado interno. (...) Eu podia dizer que perdera a perna como um "objeto interno", como uma "imago" simbólica e afetiva. Na verdade, parecia que eu precisava de ambos os conjuntos de termos, pois a perda interna em questão era tanto "fotográfica" como "existencial". Assim, de um lado, havia uma severa deficiência perceptiva, de maneira que eu perdera toda a sensação da perna. De outro, havia uma deficiência "simpática", de modo que eu perdera boa parte de meu sentimento pela perna. (...) O que poderia causar essa mudança profunda, calamitosa, esse colapso total de sentido e sentimento, esse colapso total da imagem neural - e da imago? (p. 65)

Para responder a essa questão, precisamos diferenciar imagem do corpo de esquema corporal e verificar como ambos se correlacionam com os casos apresentados.

\section{Imagem e esquema corporal}

Apesar de Sacks não dialogar frontalmente com os autores que apresentaremos a seguir, defendemos que muitas de suas hipóteses se coadunam com os conceitos da fenomenologia da percepção, que tem proposto definições de imagem e esquema corporais, muito embora, algumas dessas definições tenham sido confundidas ao longo do percurso histórico. Senão, vejamos.

Rev. Latinoam. Psicopat. Fund., São Paulo, v. 14, n. 3, p. 452-471, setembro 2011 
Segundo Morin \& Thibierge (2004) a expressão "imagem do corpo" é usada mais frequentemente para fazer referência à aparência física sobre os distúrbios de comportamentos alimentares ou a deficiência física. Ela pertence ao mesmo tempo à linguagem da neurologia, da psiquiatria e da psicanálise e adquiriu significados diferentes segundo a época, a disciplina ou os pressupostos teóricos dos diversos especialistas que a empregaram ou a empregam.

Schilder (1935) é um bom exemplo disso. Para ele, a imagem corporal é uma "figuração de nosso corpo formada em nossa mente, ou seja, o modo pelo qual o corpo se apresenta para nós" (p. 7) cuja representação é dada por várias sensações advindas da superfície do corpo, dos músculos, das vísceras etc. Por outro lado, ele define esquema corporal conforme a percepção da postura do corpo, ou seja, uma imagem tridimensional que todos nós temos de nós mesmos. Toda a construção da imagem e do esquema corporal, para Schilder, está baseada na percepção do corpo como uma unidade. Ele, portanto, faz uso dos termos como se fossem sinônimos.

Em um determinado momento, Schilder (1935) chega a afirmar que a imagem corporal pode se encolher ou se expandir e, como tal, podemos anexar objetos externos à imagem do nosso corpo. "Quando tocamos um objeto com a extremidade de uma vareta, a sensação é percebida na ponta da vareta. Esta se torna, realmente, parte da imagem corporal. Até mesmo uma peça de roupa pode mudar a imagem que temos do nosso corpo!” (p. 233). Schilder, portanto, confunde imagem com esquema corporal ao afirmar que a imagem do corpo pode incorporar objetos.

Apesar de seus estudos se darem no âmbito das lesões neurológicas, Schilder não avança na discussão quando deixa de abordar a questão pela via do mental versus físico a exemplo de outros autores, tais como apontam Costa (2004), Weiss (1999) e Gallagher (1986).

De acordo com esses autores, o corpo é um objeto intencional e consciente, logo, a imagem do corpo é uma imagem ou representação consciente, abstrata e desintegrada que se diferencia do resto do ambiente (Gallagher, 1986). Por outro lado, o esquema corporal é definido como um conjunto de sensações proprioceptivas que fornecem ao organismo sua posição gravitacional no ambiente e não apenas o seu modelo postural, no qual, através dos órgãos dos sentidos, o corpo estaria apto a agir e reagir aos estímulos do ambiente (Bermudez, 1998; Campbell, 1998).

A imagem corporal é um fato mental com três qualidades que a constitui: a) intencionalidade - pois está sempre se referindo a um outro que lhe é exterior; b) privacidade - pois é constantemente solicitada a representar à sua própria existência e o seu próprio "eu" e, por fim, c) representacionalidade - que pressupõe um mínimo de competência linguística do sujeito ou, dito de outro

Rev. Latinoam. Psicopat. Fund., São Paulo, v. 14, n. 3, p. 452-471, setembro 2011 
modo, a imagem do corpo é um processo autoperceptivo, interpessoal e linguisticamente organizado de modo reflexivo ou pré-reflexivo, consciente ou inconsciente (Costa, 2004).

Gallagher (1986) ainda afirma que a imagem do corpo inclui o corpo como ele é percebido na consciência imediata, a compreensão informada pela consciência imediata e pela compreensão intelectual do próprio corpo e, por fim, uma atitude emocional dos sentimentos do próprio corpo. Assim, a imagem corporal leva em conta o aspecto perceptivo, cognitivo e emocional.

Os incidentes de Christina e do próprio Sacks são exemplares em como a imagem corporal pode prejudicar não só a consciência do próprio corpo como o sentido de identidade pessoal. Sem o sentido da imagem do corpo ou da imagem de uma perna, conforme vimos, não é possível dar descrições narrativas de si, e quando damos, são descrições incompletas, fragmentadas, referindo-se a perda de parte do nosso eu corporal.

O esquema corporal, por outro lado, não é uma compreensão perceptiva, nem cognitiva, nem emocional; ele se distingue da imagem do corpo, pois ele é uma performance inconsciente sem uma intencionalidade. Nessa performance, o corpo adquire uma organização ou estilo em relação ao ambiente podendo incorporar objetos externos a ele. O esquema corporal é a forma como o corpo experiencia o ambiente em que se encontra. Ele envolve um conjunto de capacidades motoras, habilidades e hábitos que capacitam os movimentos e a postura do corpo no eixo gravitacional, e, como tal, é um sistema de funções motora e postural que opera em um nível inferior da intencionalidade autorreferente, muito embora essas funções possam ter uma atividade intencional (Gallagher, 1986, 1998; Gallagher \& Cole, 1995; Gallagher et al., 1998).

Para experienciar o mundo, o corpo precisa agir e para que o corpo possa agir no mundo ele necessita de uma intencionalidade e um mínimo de competência linguística para poder se representar nesse mundo.

Vários são os exemplos que podemos usar para ilustrar esse fato. $\mathrm{O}$ mais comum refere-se à vareta que um deficiente visual usa para caminhar (conforme aponta equivocadamente Schilder) - o seu corpo não se resume apenas a seus membros, mas prolonga-se até a ponta da vareta que ele usa para construir mentalmente o caminho a percorrer. Do mesmo modo, o corpo do piloto de um avião não se resume à sua matéria corporal, mas sim a toda aeronave que ele pilota. Por extensão, um exímio digitador ou pianista tem a ponta de seus dedos prolongados pelo teclado ou do computador ou do piano, praticamente incorporando esses objetos ao seu esquema corporal. É ao esquema corporal que podemos anexar objetos externos ao nosso corpo, e não à nossa imagem corporal.

Esquema e imagem corporal, portanto, são formas fenomênicas do corpo experienciar o mundo que o cerca, e participam da constituição subjetiva do nosso

Rev. Latinoam. Psicopat. Fund., São Paulo, v. 14, n. 3, p. 452-471, setembro 2011 
eu (self), por meio de uma ação sobre o mundo (intencionalidade) e de uma competência linguística (descrições narrativas de si). Com o aporte fenomenológico, unido ao conhecimento neurológico, podemos entender melhor determinados distúrbios da identidade pessoal e da imagem corporal, tal como referido pelos casos de Oliver Sacks, naquilo que ele definiu como sendo uma "neurofenomenologia do self".

Talvez Sacks não tivesse se interessado pelos distúrbios da imagem do corpo se ele mesmo não tivesse sofrido um distúrbio dessa natureza, o qual afetou diretamente a atividade neural organizada para formar a imagem do corpo em seu cérebro. E foi essa experiência que o fez prestar atenção no discurso de seus pacientes.

Eu agora podia acolher totalmente as experiências de meus pacientes, entrar em imaginação em suas experiências e ser acessível e "receptivo" naquelas regiões tenebrosas. Eu ouviria meus pacientes como nunca antes - suas gaguejantes, mal-articuladas comunicações enquanto eles faziam a jornada por uma região que eu conhecia tão bem. (Sacks, 2003, p. 173)

A possibilidade de usarmos as ferramentas do conhecimento neurológico e da fenomenologia da percepção, tais como descrevemos acima, aliado ao nosso conhecimento das teorias da subjetividade e das descrições narrativas de si, seja um caminho que se abre notadamente para o tratamento de pacientes com distúrbios neurológicos ou com distúrbios de imagem corporal, tal como fez Sacks ao longo de anos de trabalho com seus pacientes.

\section{Considerações finais}

Oliver Sacks, ao longo do seu percurso, estudou inúmeros casos de deficiência sensitiva ou motora de mãos e pés, decorrentes ou de lesões cerebrais ou de anestesia local, ou de outros tipos de doenças mais graves, como tumor, diabetes ou câncer terminal. Em outros estudos, ele também analisou os casos de membros fantasmas, cuja imagem corporal fora afetada, encontrando correlação direta com distúrbios de recepção e representação da imagem no córtex cerebral.

Mais do que isso, Sacks também analisou distúrbios severos da imagem corporal e do ego corporal em consequência de lesão, doença ou distúrbios periféricos no lobo cerebral, afirmando que todo paciente com graves danos na imagem corporal apresentava distúrbios igualmente severos no ego corporal.

A experiência ontológica desses sujeitos com dissoluções ou aniquilações do ser nas partes afetadas, fizeram com que houvesse uma alteração da identidade 
ou na percepção de si mesmo, com um fundamento neurológico, orgânico e nitidamente definido.

Em nenhum desses distúrbios foi descartado exames neurológicos mais apurados, baseados em técnicas de imageamento do cérebro, PET Scans, ou magnetoencefalografia em 3D. No entanto, descrever experiências subjetivas, resultantes de danos cerebrais a partir das técnicas de imagem cerebral, para Sacks, não daria conta da singularidade de cada um de seus pacientes, nem apontaria para o seu sofrimento psíquico e do seu próprio "eu":

O organismo é um sistema unitário, mas o que é um sistema para um self vivo, real? A neuropsicologia fala de "imagens internas", "esquemas", "programas" etc., mas os pacientes falam de "experimentar", "sentir", "tencionar" e "agir". A neuropsicologia é dinâmica, mas ainda é esquemática, ao passo que as criaturas vivas, no todo, têm um self - e são livres. Isso não equivale a negar que há sistemas envolvidos, e sim a dizer que os sistemas estão embutidos no self e que o self transcende esses sistemas. (...) A neuropsicologia é admirável, mas exclui a psique - exclui o "eu" vivo, ativo, que tem experiências. (...) O caráter objetivo e empírico da neurologia impossibilita considerações do sujeito, do "eu". (...) O que precisamos agora, e precisamos para o futuro, é de uma neurologia do self, da identidade. (Sacks, 2003, p. 181-182)

Podemos dizer com isto que, em certo sentido, Sacks "humanizou" a neurologia ao dar voz a seus pacientes com distúrbios neurológicos, em busca da recuperação de uma certa normalidade e de sua subjetividade, ao passo que transformou a ciência neurológica em uma disciplina mais ética e mais humana, "despatologizando" a maioria dos seus pacientes e transformando a experiência subjetiva encarnada não na materialidade do cérebro, mas na materialidade do corpo humano como um todo (Couser, 2001).

Se por um lado, Sacks não cria nenhuma grande teoria para explicar e comprovar a construção da imagem do corpo fora dos registros neurológicos e neurocientíficos, de acordo com as recentes descobertas possibilitadas pela tecnologia médica disponível, por outro, ele ressalta a importância de teorias do campo fenomenológico para descrever e compreender o mais amplamente possível as experiências subjetivas.

A construção da imagem do corpo, para ele, é resultante de uma descrição da experiência subjetiva, do reconhecimento de um sujeito como campo da ação. Ehrenberg (2004) ressalta essa perspectiva ao afirmar que seria necessário distinguir dois campos nitidamente distintos quanto às doenças neurológicas que opõem o cerebral ao relacional, recrudescendo a perspectiva de Sacks, por tornar a neurologia "mais solidária" a seus pacientes. Em neurologia, os problemas psicopatológicos ou distúrbios funcionais são suscitados por causas ou biológicas ou inerentes à própria doença. Nesse sentido, Sacks participa dessa perspectiva 
ao mostrar a necessidade de uma investigação clínica e profunda sobre a compreensão psicológica de seus pacientes.

Assim, o que Sacks propõe não é a compreensão da subjetividade humana, da identidade e da construção da imagem do corpo a partir de uma entidade exterior ao corpo. O cérebro é um órgão integrado à visceralidade da matéria do próprio corpo e, como tal, necessita desse corpo e de todos os seus dispositivos necessários para conhecer, reconhecer e decodificar todos os estímulos providos pelo ambiente e pela interioridade de sua carne, construindo imagens de si, narrativas de si e fundamentando o seu "eu" e a sua identidade a partir do seu equipamento linguístico. Com isso, Sacks (2003) quebra definitivamente o modelo clássico do dualismo cartesiano e aponta para uma possível compreensão de uma neurologia mais voltada para a identidade do que para as descrições dos distúrbios neurológicos:

Não existe representação de "espaço" abstrato no cérebro - apenas de nosso "espaço pessoal" próprio. (...) Nosso corpo é pessoal - que é o primeiro definidor do ego ou self ("O ego é sobretudo um ego corporal", escreveu Freud). A neurologia baseia-se ainda em um modelo mecânico. O modelo mecânico remonta Descartes, à sua divisão dicotômica entre corpo e alma, sua concepção do corpo como um autônomo, com um "eu" que sabe - tenciona pairando de alguma forma sobre o corpo. (p. 206)

Freud foi aquele que quebrou barreira do campo neurológico à sua época e apontou para uma nova forma de ver o sujeito sem os grilhões da neurologia oitocentista.

Sacks, por seu turno, tentou apontar para um novo campo da ciência do século XXI, qual seja, a possibilidade de uma "neurologia romântica" como ele bem a definiu no início de seus estudos, ou quem sabe, uma "neurologia da identidade", uma "neurologia do self" ou ainda uma "neurologia do "eu",

No campo da subjetividade, não podemos nos fechar para os avanços que as ciências médicas têm proposto para as nossas certezas diante da mente e da alma humana. Aprender com o olhar clínico de pesquisadores como Oliver Sacks, é se abrir para as mudanças que Freud já havia referido na primeira metade do século passado e buscar, na atualidade, novas narrativas da mente.

\section{Referências}

Bermudez, J. L.; Marcel, A.; Eilan, N. Self-counsciousness and the body: an interdiciplinary introduction. In: Bermudez, J. L.; Marcel, A.; EIlAn, N. (Eds.). The 
body and the self. Cambridge/Massachusetts: The Massachusetts Institute of Technology Press, 1998. p. 1-28.

Butterworth, G. An ecological perspective on the origins of self. In: Bermudez, J. L.; Marcel, A.; EIlan, N. (Eds). The body and the self. Cambridge/Massachusetts: The Massachusetts Institute of Technology Press, 1998. p. 87-105.

Campbell, J. The body image and self-counsciouness. In: Bermudez, J. L.; Marcel, A.; EILAn, N. (Eds). The body and the self. Cambridge/Massachusetts: The Massachusetts Institute of Technology Press, 1998. p. 29-42.

Costa, J. F. O vestígio e a aura: corpo e consumismo na moral do espetáculo. Rio de Janeiro: Garamond, 2004.

COuSER, G. T. The cases of Oliver Sacks: the ethics of neuroanthropology. Lecture presented at The Poynter Center, Indiana University, Bloomington, Indiana, October 24, December, 2001, p. 1-13. Disponível em: <http://poynter.indiana.edu/publications/ m-couser.pdf> . Acesso em: 16 dez. 2006.

EHRENBERG, A. Le sujet cerebral. Esprit, Paris, n. 309, p. 130-155, Novembre/2004.

FREUd, S. (1886). Observação de um caso grave de hemianestesia em um homem histérico. In: Edição Standard Brasileira das Obras Psicológicas Completas de Sigmund Freud. Rio de Janeiro: Imago, 1996. V. I.

. (1888a). Brain. In: Solms, M.; SAling, M. A moment of transition: two neuroscientific articles by Sigmund Freud. London: Karnac Books/The Institute of Psychoanalysis, 1990. p. 39-85.

. (1888b). Histeria. In: Edição Standard Brasileira das Obras Psicológicas

Completas de Sigmund Freud. Rio de Janeiro: Imago, 1996. V. I.

. (1891a). Contribution à la conception des aphasies. Paris: PUF, 1987.

. (1895). Projeto para uma psicologia científica. In: Edição Standard Brasileira das Obras Psicológicas Completas de Sigmund Freud. Rio de Janeiro: Imago, 1996. V. I.

Gallagher, S. Body image and body schema: a conceptual classification. Journal of Mind and Behaviour, n. 7, p. 541-554, 1986.

. Body schema and intentionality In: Bermudez, J. L.; Marcel, A.; Eilan, N. (Eds). The body and the self. Cambridge/Massachusetts: The Massachusetts Institute of Technology Press, 1998. p. 225-266.

Gallagher, S.; Cole, J. Body image and body scheme in a deafferented subject. Journal of Mind and Behaviour, n. 16, p. 369-389, 1995.

GALlAGHER, S. et al. Hand-mouth coordination, congenital absense of limb, and evidence for innate body schemas. Brain and Cognition, n. 38, p. 53-65, 1998. 
LÚRIA, A. R. Fundamentos de neuropsicologia. Rio de Janeiro/São Paulo: Livros Técnicos e Científicos/Edusp, 1981.

Morin, C.; Thibierge, S. L'image du corps en neurology: de la cénesthésie à l'image spéculaire. Apports Cliniques et Théoriques de la psychanalyse. L'Évolution Psychiatrique, n. 69, p. 417-430, 2004.

SACKs, O. Um antropólogo em Marte. São Paulo: Companhia das Letras, 1995. . O homem que confundiu sua mulher com o chapéu. São Paulo: Companhia das Letras, 1997. . Com uma perna só. São Paulo: Companhia das Letras, 2003.

SCHILDER, P. (1935). A imagem do corpo: as energias construtivas da psique. São Paulo: Martins Fontes, 1999.

Varela, F. J. Neurophenomenology: A methodological remedy to the hard problem. Journal of Consciousness Studies, v. 3, n. 4, p. 330-350, 1996.

VARela, F. J.; Shear, J. First-person accounts: why, what, and how. In: Varela, F. J.; SHEAR, J. (Eds.). The View from Within: First-Person Approaches to the Study of Consciousness. Thorveton, UK: Imprint Academic, 1999. p. 1-14.

WeIss, G. Body images: embodiment as intercorporeality. New York/London: Routledge, 1999.

(Oliver Sacks and "neurophenomenology of the self")

Neurology is a branch of medicine that studies a variety of neurological disorders that affect speech, language, memory vision, perception of the sense of identity, and other neurological factors. Neurology has produced a specific body of knowledge ranging from the development of medical technology to modern brain imaging devices. This paper examines some of the contributions by Oliver Sacks through what he has defined as "neurophenomenology of the self," or of subjectivity, identity and body image. This study highlights his phenomenological approach with contributions from neurology and emphasizes the role of subjectivity in the search for new narratives of the mind.

Key words: Neurophenomenology, self, subjectivity, identity, body image

(Oliver Sacks et la "neurophénoménologie du soi")

La neurologie est une branche de la médecine qui cherche à étudier toute une gamme de troubles neurologiques comme la perte de la parole, du langage, de la 
mémoire, de la vision, de la perception sensorielle et de l'identité, entre autres. Elle construit un ensemble de connaissances spécifiques, surtout à partir du développement de la technologie médicale, plus précisément à l'aide d'appareils d'imagerie cérébrale. Cet article vise à analyser les contributions du neurologue Oliver Sacks à partir de ce qu'il décrit comme la "neurophénoménologie du soi", la subjectivité, l'identité et l'image corporelle. Cette étude met en évidence l'approche phénoménologique, les contributions de la neurologie, ainsi que le rôle de la subjectivité pour repérer de nouvelles narratives de l'esprit.

Mots clés: Neurophénoménologie, soi, subjectivité, identité, image du corps

(Oliver Sacks y la "neurofenomenologia del self")

La neurología es una rama de la medicina que tiene como objetivo estudiar diversos trastornos neurológicos, tales como la pérdida del habla, del lenguaje, de la memoria, de la visión y de la percepción de los sentidos de identidad, entre otros trastornos neurológicos, así como también ha construido un conjunto de conocimientos específicos, especialmente a partir del desarrollo de la moderna tecnología médica a través de dispositivos de imagen cerebral. Este estudio tiene como objetivo examinar las contribuciones del neurólogo Oliver Sacks de lo que él definió como una "neurofenomenologia del self", de la subjetividad, de la identidad y de la imagen corporal. Se evidencia el enfoque fenomenológico en conjunto con las contribuciones de la neurología y se hace destaque al papel de la subjetividad en la búsqueda de nuevas narrativas de la mente.

Palabras clave: Neurofenomenologia, self, subjetividad, identidad, imagen corporal

Citação/Citation: SILVA, S. G. DA. Oliver Sacks e a "neurofenomenologia do self”. Revista Latinoamericana de Psicopatologia Fundamental, São Paulo, v. 14, n. 3, p. 452-471, set.2011.

Editor do artigo/Editor: Prof. Dr. Manoel Tosta Berlinck

Recebido/Received: 14.9.2010/9.14.2010 Aceito/Accepted: 25.11.2010/11.25.2010

Copyright: (C) 2009 Associação Universitária de Pesquisa em Psicopatologia Fundamental/ University Association for Research in Fundamental Psychopathology. Este é um artigo de livre acesso, que permite uso irrestrito, distribuição e reprodução em qualquer meio, desde que o autor e a fonte sejam citados/This is an open-access article, which permits unrestricted use, distribution, and reproduction in any medium, provided the original author and source are credited.

Rev. Latinoam. Psicopat. Fund., São Paulo, v. 14, n. 3, p. 452-471, setembro 2011 


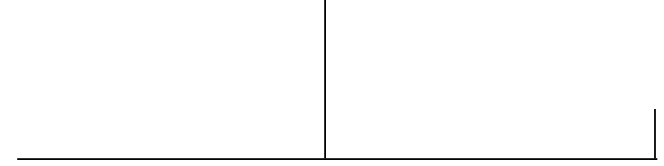

Financiamento/Funding: $\mathrm{O}$ autor declara não ter sido financiado ou apoiado/The author has no support or funding to report.

Conflito de interesses/Conflict of interest: $O$ autor declara que não há conflito de interesses/The author declares that has no conflict of interest.

\section{Sergio Gomes da Silva}

Doutorando do Programa de Pós-Graduação em Psicologia Clínica da Pontifícia Universidade Católica do Rio de Janeiro - PUC-RIO (Rio de Janeiro, RJ, Br); Mestre em Saúde Coletiva pelo Instituto de Medicina Social da Universidade do Estado do Rio de Janeiro - UERJ (Rio de Janeiro, RJ, Br); Pesquisador do Núcleo de Estudos e Pesquisa em Tanatologia e Subjetividade da Universidade Federal do Rio de Janeiro - NEPTS/UFRJ (Rio de Janeiro, RJ, Br); Psicanalista; Psicólogo da Divisão de Psicologia Aplicada Profa. Isabel Adrados do Instituto de Psicologia da Universidade Federal do Rio de Janeiro - UFRJ (Rio de Janeiro, RJ, Br); Membro Associado e Psicoterapeuta Voluntário da Clínica Social do Instituto de Estudos da Complexidade - IEC (Rio de Janeiro, RJ, Bra).

Av. Pasteur, 250 - Botafogo

22290-240 Rio de Janeiro, RJ, Brasil

Fones: (21) 3873-5326 / 5327 ou (21) 2295-8113

e-mail: sergiogsilva@uol.com.br.

Rev. Latinoam. Psicopat. Fund., São Paulo, v. 14, n. 3, p. 452-471, setembro 2011 